\title{
The blood-uterine lumen barrier and exchange between extracellular fluids
}

\author{
Ann C. McRae* \\ Department of Medical Biochemistry, University of Calgary, Calgary, Alberta, Canada T2N $4 N 1$
}

\begin{abstract}
Summary. The concept of a blood-tissue barrier defines the rates at which matter exchanges among the vascular and extravascular fluids of the tissue. The remarkably slow rates at which substances such as mannitol $\left(M_{\mathrm{r}} 182\right)$ enter uterine fluid from plasma demonstrate the existence of a blood-uterine lumen barrier. Available evidence indicates that the uterine microvascular endothelium and the uterine epithelium behave as lipoid layers interrupted by water-filled channels. Furthermore, both cell layers appear to select actively certain substances over others for exchange with opposing extracellular fluids. In contrast to these similarities, the uterine epithelium and endothelium differ considerably with regard to restrictiveness. For most substances the primary rate-limiting boundary between blood and the uterine lumen is the epithelium. The extracellular fluid compartments of the lumen and endometrium are also influenced by the internalization and release of materials into and out of intracellular compartments including those of the stromal and migratory cells of the endometrium, the epithelium and the developing conceptus. Considerable evidence suggests that the luminal milieu of the developing embryo is created and maintained by the transport and permeability properties of the blood-uterine lumen barrier in conjunction with the cellular activities of the endometrium and embryo. This milieu probably fulfils the informational and nutritional needs of the developing embryo.
\end{abstract}

Keywords: uterine epithelium; uterine vasculature; barrier, permeability; exchange; uterine environment; embryo development

\section{Introduction}

Mammalian embryos are responsive to environmental conditions. The nature of their environment in utero can affect their growth and differentiation as blastocysts. The uterine luminal environment, in which embryos are free-lying from the time they enter the uterus until a definitive attachment is formed to the uterine wall, is primarily permissive and facilitative. It is permissive because deviations in environmental conditions either have little effect or cause cessation of development and, except during the quiescence of delayed implantation, loss of viability. Furthermore, environmental disturbances have the ability to diminish profoundly embryonic viability, presumably due to luminal conditions exceeding the limits of tolerance of developing embryos. It is facilitative because by its nature it apparently enhances blastocyst expansion, elongation and differentiation. Therefore, the mechanisms whereby the uterine luminal environment is regulated are of potential importance to embryo survival and fertility.

The concept of a blood-tissue barrier, which arose early in this century, can be applied advantageously to the mammalian uterus. This concept of a barrier between blood and a tissue such as brain, testis or uterus defines the rates at which matter exchanges among the vascular and extra-

*Present address: Department of Physiology, College of Medicine, University of Saskatchewan, Saskatoon, Saskatchewan, Canada S7N 0W0. 
vascular fluids of the tissue. For example, low molecular weight substances in plasma such as thiocyanate, creatinine, sucrose and $p$-aminohippurate penetrate into the cerebrospinal fluid so slowly that the ratios of cerebrospinal fluid to plasma concentrations are less than 1.0 although plasma concentrations are constant for several hours. This slow penetration of the cerebrospinal fluid demonstrated the existence of a permeability barrier between blood and cerebrospinal fluid (Davson, 1955). Similarly, a blood-testis barrier was demonstrated by the observations that certain substances infused intravenously either did not enter rete testis fluid ( $p$-aminohippurate, glutamate, iodinated albumin, inulin and radiolabelled EDTA) or did so only at slow rates (thiocyanate, creatinine, galactose) (Setchell et al., 1969). Likewise, the evidence for a blood-uterine lumen barrier is direct: in rats and rabbits, low molecular weight substances (sodium, tetraethylammonium, mannitol, sucrose and inulin) and iodinated albumin do not equilibrate between uterine fluid and plasma despite prolonged maintenance of relatively constant plasma concentrations (Marley \& Robson, 1971; Conner \& Miller, 1973; Kulangara, 1976; McLachlan et al., 1976; McRae \& Kennedy, 1979, 1983a). The presence of a barrier within the uterus is demonstrated by the remarkably slow rates at which certain substances such as mannitol (Fig. 1) penetrate from the vascular fluid of the uterus into the uterine luminal fluid.

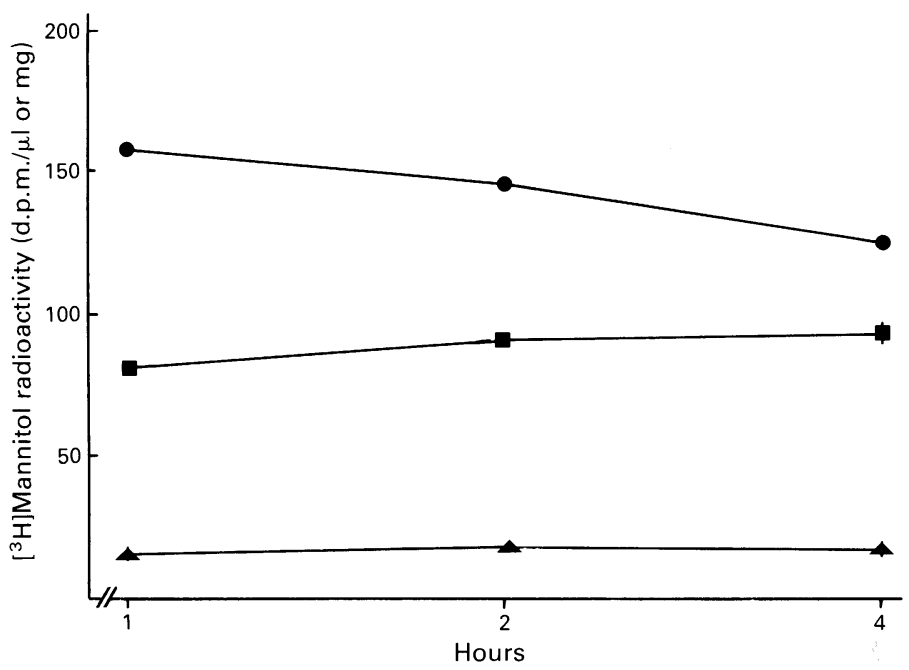

Fig. 1. Time courses for radioactivity concentrations in serum $(\bullet)$, uterine tissue $(\boldsymbol{\square})$ and uterine fluid $(\boldsymbol{\Delta})$ (d.p.m./mg) after single intravenous injections of $\left[{ }^{3} \mathrm{H}\right]$ mannitol into ovariectomized, oestrogen-treated rats with ligated pedicles. Diffusion of mannitol from blood into uterine fluid is markedly restricted as indicated by the differences between serum and uterine fluid radioactivity concentrations. Ratios of uterine tissue to serum radioactivity concentrations are $\geq 0.45$, indicating volumes of distribution of $0.45 \mu 1 / \mathrm{mg}$ or greater (from McRae \& Kennedy, 1983a.)

An important asset of the concept of a blood-uterine barrier is that the extracellular fluid of the uterus can be appropriately divided into several compartments. In this paper those of the endometrium only will be considered; i.e. the vascular, endometrial extracellular, endometrial intracellular and luminal extracellular fluids. (The blood cells will not be considered until they have migrated into the extravascular space.) The barrier which divides uterine extracellular fluid into compartments is not absolute because material does exchange between compartments (thus validating a compartmental analysis). Therefore, each extracellular fluid compartment influences those compartments with which it exchanges material. These bidirectional relationships for the endometrium are summarized in Fig. 2. Thus, the permeability and transport properties of the 

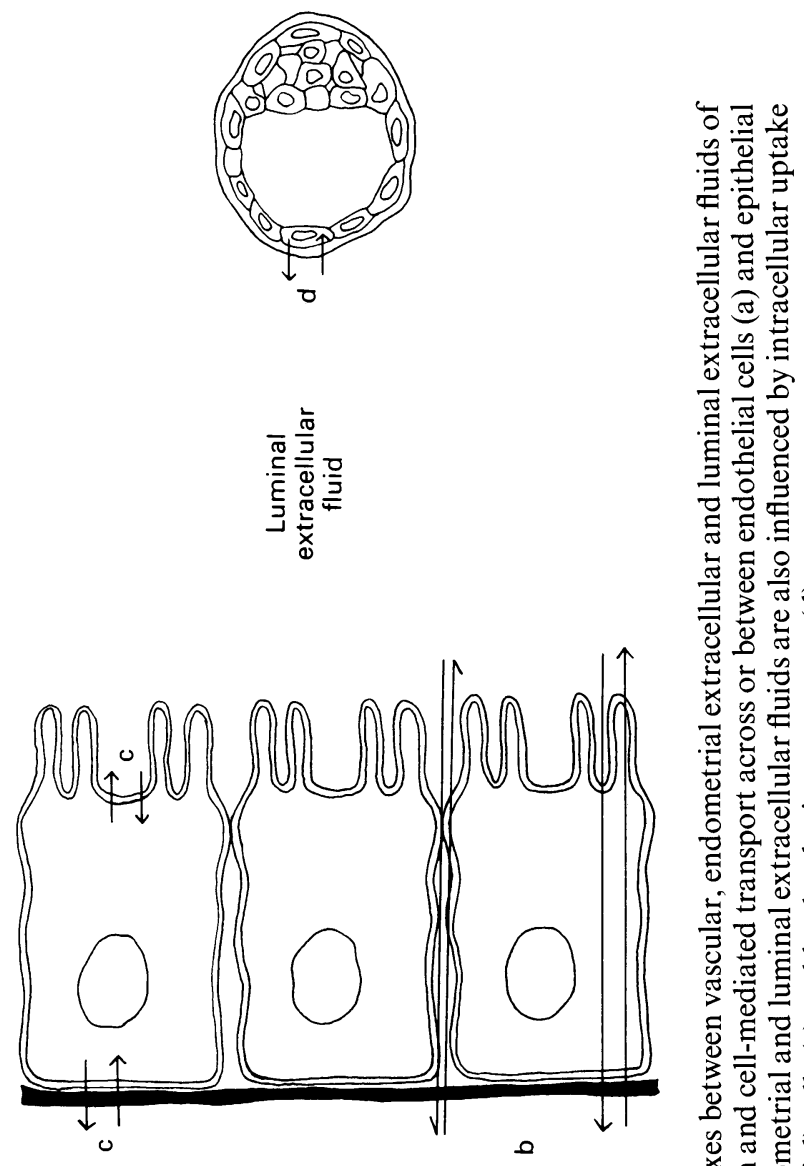

홍ำ

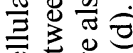

ठํำ

娄娄

桴造

인

政

है 형

की

可

흘 정

芯䓠

¿

ष두

उ

额芯

ํㅣㄹ 음

을을

䒠武言 음 过昰氞

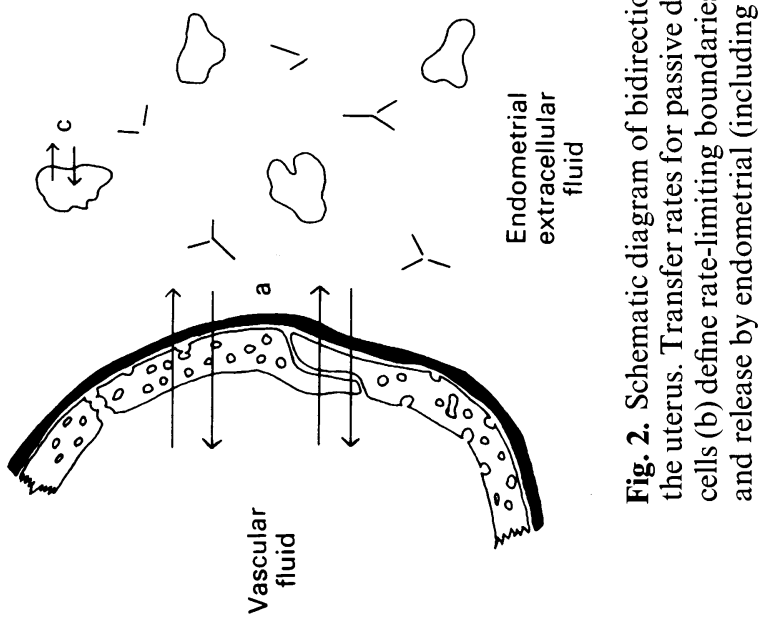


endothelial cells of the microvasculature (a) and of the epithelial cells lining the lumen (b) determine the rate-limiting boundaries between the extracellular fluid compartments of the endometrium and lumen. These extracellular fluid compartments are also influenced by the uptake and release of materials into and out of the intracellular fluid compartments of endometrial (including epithelial) cells (c) and the cellular components of the developing embryo (d). In this scheme the interstitial concentrations will influence the intercompartmental exchange both of substances which primarily diffuse across the rate-limiting boundaries and those which are transported by specific mechanisms, the kinetics of which are highly dependent upon ambient concentrations. Furthermore, because a blood-uterine lumen barrier exists, compounds common to these compartments are likely to be present in some at markedly different concentrations, even under steady-state conditions.

The existence of a blood-uterine barrier implies that the immediate milieu of the developing embryo might be a fluid which is unique in character and which is specialized to fulfil the nutritive and information requirements of the embryo. Because the embryo is growing and differentiating, and likely to require a changing complex of environmental signals, its luminal milieu may also evolve. Available evidence (see McRae, 1984) indicates that the uterine luminal milieu is dynamic in that the composition of uterine fluid exhibits marked differences between stages of the oestrous cycle and between the oestrous cycle and pregnancy. That is, the microenvironment of the uterine lumen at oestrus differs fundamentally from the one which evolves in the course of the preimplantation and peri-implantation periods of gestation. Thus, the elaboration of the developmental programme of peri-implantation embryos might be enhanced by the dynamic nature of the luminal extracellular fluid.

Blood-tissue barriers in biological systems probably create and maintain specialized environments within their boundaries. The primary objective of this review is to examine the cellular structures and processes involved in (a) defining the rates at which materials exchange among the uterine extracellular fluids and (b) modifying these fluids by internalizing and releasing material between intracellular and extracellular fluid compartments. In particular the dynamic nature of these cellular structures and processes with regards to hormonal and pregnancy-related regulation are considered. In doing so, much of the available literature has been reviewed. An additional objective is to examine how these processes contribute to the uniqueness of each extracellular fluid, particularly that of the uterine lumen. Lastly a brief mention will be made of a role for extrinsic factors in blastocyst differentiation.

\section{Permeability and transport properties of uterine endothelium}

The ability of the microvasculature to act as a rate-limiting boundary between blood and tissue differs widely from one tissue to another (Dewey, 1959). Available evidence indicates that uterine vascular permeability, especially to proteins, varies markedly, depending upon reproductive condition. That is, uterine vascular permeability, similar to that of lung, brain or muscle as opposed to gut, liver or skin, exhibits considerable restrictiveness (Hechter et al., 1942) except under the influence of oestrogen or during implantation. Like all endothelia (Hormia \& Virtanen, 1986) the endothelium of the uterus is more than a passive, semipermeable barrier between vascular and extravascular fluids. Indeed, it appears to select actively certain proteins over others for exchange with extravascular fluid. Furthermore, the rate at which the endothelium is perfused appears likely to potentiate the vascular-extravascular exchange of certain substances. Thus, the uterine endothelium appears to be a dynamically active boundary between blood and the uterine endometrium.

Ultrastructural studies of endometrial capillaries and post-capillary venules indicate that the endothelium in this tissue is both continuous and fenestrated, depending upon the endocrine or reproductive status of the animal. In ovariectomized, progesterone-treated and metoestrousdioestrous mice the endometrial endothelium is continuous with few or no fenestrations and the 
intercellular clefts between adjoining cells are sealed by tight junctions (Castillo-Jessen \& GonzalezAngulo, 1973; Martin et al., 1973). Furthermore, by as late as $6 \mathrm{~h}$ after intravenous injection of horseradish peroxidase $\left(M_{\mathrm{r}} 40000\right.$; Einstein-Stokes radius (ESR) $\left.3.0 \mathrm{~nm}\right)$ to metoestrousdioestrous mice, no reaction product is observed outside the vascular lumen (Castillo-Jessen \& Gonzalez-Angulo, 1973), demonstrating a marked impermeability of these junctions. By contrast, in oestrogen-treated mice and rats the endothelium is fenestrated to a greater extent (Martin et al., 1973) and intercellular gaps are frequently observed (Ham et al., 1970). Furthermore, these intercellular endothelial clefts in pro-oestrous-oestrous mice are clearly permeable to horseradish peroxidase since enzyme activity is apparent in vascular lumen, intercellular clefts and perivascular space as early as $1 \mathrm{~min}$ after intravenous injection (Castillo-Jessen \& Gonzalez-Angulo, 1973). Differences in endothelial structure and permeability between implantation and non-implantation tissue are also apparent. The venous capillaries and post-capillary venules of implantation sites in rats disclose fenestrations and intercellular gaps which are not present in non-implantation sites (Abrahamsohn et al., 1983). With regard to permeability, the uterine vasculature of ovariectomized rats (Szego \& Roberts, 1953) and rabbits is relatively impermeable to trypan blue- or Evans bluealbumin complexes as is that of lung, brain and muscle (Hechter et al., 1942). However, in response to oestrogen, a transient increase in vascular permeability to plasma proteins is observed which peaks about $6 \mathrm{~h}$ after oestrogen and is much reduced by $20 \mathrm{~h}$ (Szego \& Roberts, 1953; Sullivan \& Wira, 1982; Finlay et al., 1981). An accumulation of vital dye has also been observed in the vicinity of implanting blastocysts in rats, mice, rabbits, hamsters (Psychoyos, 1973) and pigs (Keyes et al., 1986). There is therefore considerable correspondence between the ultrastructure and permeability to proteins of the uterine microvasculature. However, subtle differences between oestrogen- and blastocyst-induced increased vascular permeability might exist. That is, the former is thought to result from gaps forming between endothelial cells of capillaries (Ham et al., 1970), whereas the latter is thought to be due to gaps forming between endothelial cells of the terminal portions of capillaries and mainly in the first part of the venule system (i.e. vessels of $>5 \mu \mathrm{m}$ diameter) (Abrahamsohn et al., 1983). Whether this discrepancy between the role of capillaries and venules between oestrogen- and implantation-induced vascular permeability represents an essential difference remains to be determined. Nevertheless, it is notable that the blastocyst-induced changes resemble the vascular leakage which occurs during inflammation when the post-capillary (pericytic) venules with diameters ranging between 5 and $10 \mu \mathrm{m}$ contract and pull away from each other (Joris et al., 1987). Thus, uterine capillaries and venules are relatively impermeable to plasma proteins except during specific but transient responses to oestrogen and to a localized response to implanting blastocysts.

Vascular-extravascular exchange of protein by passive diffusion is probably governed by molecular sieving (i.e. diffusion which is restricted due to molecular size). This is because vascular permeability to water-soluble molecules is likely to occur via transendothelial 'pores' of two sizes. There is a large number of small pores (approximately $3.0-3.5$ or $4.5 \mathrm{~nm}$ in radius) which are impermeable to dextrans, glycogens, ferritin and possibly albumin but are permeable to horseradish peroxidase, and a small number of large pores $(25-35 \mathrm{~nm}$ in radius) which are permeable to all of the above marker proteins. In the ileo-jejunum the morphological equivalents of the large pores are thought to be diaphragmed fenestrae, channels and vesicles (see Pino, 1985). Macromolecules of a radius similar in magnitude to the dimensions of available pores will penetrate them but only at relatively slow transfer rates, due to steric hindrance. Conversely, molecules which are considerably smaller than these pores will penetrate them at much faster transfer rates, due to minimal steric hindrance. Therefore, passive diffusion governed by molecular sieving will be suggested by vascular-extravascular transfer rates which vary inversely with molecular size.

In the uterus the vascular-extravascular exchange of plasma proteins has been studied specifically for relatively few proteins. For example, the endometrial microvasculature of mice on Day 1 of pregnancy (Day 1 = day of vaginal plug and is equivalent to oestrus) is permeable to FITClabelled proteins such as apoferritin (ESR 6.1 nm), immunoglobulin G, albumin, haemoglobin and 
$\alpha$-lactalbumin (Parr, E. L. \& Parr, M. B., 1986). Furthermore, in that study discrete loci of fluorescence were apparent in epithelial cells more quickly after intravenous administration of smaller proteins (haemoglobin and peroxidase) than larger ones (apoferritin and IgG). In a different study (Finlay et al., 1981) the extravasation of fibrinogen $\left(M_{\mathrm{r}} 340000\right)$ was considerably less than that of radiolabelled albumin $\left(M_{\mathrm{r}} 68000\right)$ in immature mice treated with or without oestrogen. It is pertinent then that these observations are consistent with the endometrial microvasculature selectively restricting the passage of some proteins on the basis of molecular size.

However, certain discrepancies between relative rates of transfer from plasma to extravascular fluid and molecular sizes have been reported (Finlay et al., 1981), and suggest that exchange of some plasma proteins occurs via a pathway which does not discriminate on the basis of molecular size (weight). Firstly, when plasma concentration differences were taken into account, it is apparent that $\alpha_{2}$-macroglobulin $\left(M_{\mathrm{r}} 720000\right)$ accumulated in uterine tissue to greater extents than other proteins such as albumin $\left(M_{\mathrm{r}} 68000\right)$ and fibrinogen $\left(M_{\mathrm{r}} 340000\right)$. Secondly, the enhanced accumulation of $\alpha_{1}$-protease inhibitor $\left(M_{\mathrm{r}} 53000\right)$ in response to oestrogen-increased vascular permeability was markedly greater than that of a smaller protein, soybean trypsin inhibitor $\left(M_{\mathrm{r}} 22000\right)$. These observations suggest that some proteins are transferred across uterine endothelium via pathways which select some proteins on the basis of factors in addition to molecular size. It is pertinent that a 'transcytotic' pathway has been proposed to account for most macromolecular transport across the microvascular endothelium (Simionescu, 1979). In this type of transport, plasmalemmal vesicles are formed at one membrane, and are translocated to the opposing membrane. There they fuse with the plasma membrane and release their contents into the extravascular fluid. An important implication of a transcytosis pathway across endothelia is that specificity for certain plasma proteins or classes of proteins could be conferred by means of specific receptors on the cell surfaces of these cells. Colloidal gold-labelling studies demonstrate end thelial binding and endocytosis of a range of plasma proteins including ceruloplasmin, low-density lipoproteins, galactosyl-albumin, ion-transferrin complexes and a variety of coagulation factors (see Handley \& Chien, 1987). Collectively, these observations suggest that certain proteins might be selected by the uterine endothelium for transport across these cells via a transcytotic pathway.

Current evidence provides indirect support for potentially important roles of some plasma proteins in endometrial physiology. Growth factors and growth factor-like substances, perhaps of plasma origin, might be required for optimal endometrial differentiation. This is based upon specific binding receptors for epidermal growth factor (EGF) having been described for human (Hoffmann et al., 1984) and rat (Mukku \& Stancel, 1985) uterus. In addition to EGF, insulin binding has been reported for human uterus (Sheets et al., 1985). Furthermore, a marked deficiency of oestrogen responses occurs in diabetic rats perhaps due to the absence of a 'positive regulating' interaction between insulin and oestrogen (Frederick et al., 1985). Lastly, extravasation of plasma protein and extravascular clotting might be important factors before modified tissue growth responses including tumour growth and angiogenesis (Dvorak et al., 1985) and therefore might play a role in decidualization of the stroma. Thus, vascular-extravascular exchange of these proteins and others might influence certain aspects of endometrial physiology.

Studies of the behaviour of the uterine microvasculature towards substances with molecular weights of $<5000$ indicate that this rate-limiting boundary is freely permeable to these substances. This permeability to small molecules is demonstrated by uterine volumes of distribution for inulin $\left(M_{\mathrm{r}} 5200\right)$, sucrose $\left(M_{\mathrm{r}} 342\right)$ and mannitol $\left(M_{\mathrm{r}} 182\right)$ which achieve steady state within $1 \mathrm{~h}$ of intravenous administration to oestrogen-treated rats (McRae \& Kennedy, 1983a) and are consistent with an extracellular fluid distribution (Larsson et al., 1980). Verheugen et al. (1984), however, indicate that the transfer rates of small molecules are influenced by lipid solubility. Uterine extractions of unconjugated oestrogens during single circulations through the uterus (i.e. $15 \mathrm{sec}$ after administration) in ovariectomized rats were 5-fold greater than those for oestrogens conjugated to sulphates or glucuronidates. Since conjugation increases the number of hydrogen bonds formed in water, conjugated steroids are much more hydrophilic than unconjugated ones (Verheugen et al., 
1984). The uterine microvasculature therefore appears to be less permeable to hydrophilic substances than lipophilic ones. This characteristic suggests that the endothelium behaves as a lipoid layer interrupted by water-filled channels. As noted above, the permeability of these water-filled channels to proteins appears to be increased by oestrogen treatment and during implantation. In ovariectomized rats oestrogen increases the rates of passage of urea $\left(M_{\mathrm{r}} 60\right)$ and sucrose $\left(M_{\mathrm{r}} 342\right)$ from blood into uterine tissue (Kalman et al., 1961). Since oestrogen treatment increases vascular permeability to proteins, increased transfer rates for sucrose and urea might also result from increased permeability. Alternatively, because oestrogen in rats causes marked increases in uterine blood flow (Harvey \& Owen, 1976) in addition to vascular permeability, and because flow can be a limiting factor for substances with large permeability coefficients, increased transfer rates for small molecules like sucrose and urea in response to oestrogen could result also from increased uterine blood flow. Lipid solubility and uterine blood flow might therefore be important factors influencing the rates at which small molecules $\left(M_{\mathrm{r}}<5000\right)$ exchange between vascular and extravascular fluids in the uterus.

Therefore, the endothelium has the ability to function as a rate-limiting boundary by virtue of its relatively limited permeability combined with probable specific transport mechanisms. Also by virtue of these properties the endothelium has the potential to enhance or accentuate extravascular exchange of certain plasma components over others, thus providing a degree of specialization to endometrial extravascular, extracellular fluid.

\section{Permeability and transport properties of uterine epithelium}

The ability of the uterine epithelium to perform as a rate-limiting boundary is considerably greater than that of the uterine endothelium. This barrier is selectively permeable to substances primarily on the basis of molecular size and lipid solubility. In addition, available evidence indicates this barrier has the ability to concentrate some substances in luminal extracellular fluid. Other evidence is consistent with selective transport of certain macromolecules. Generally these permeability and transport activities vary in accordance with reproductive status. Thus, the uterine epithelium is also a dynamically active barrier between endometrial and luminal extracellular fluids and probably exerts considerable influence over the nature of luminal extracellular fluid.

The uterine epithelium is a simple epithelium composed of columnar cells which are joined apically by tight junctions. The complexity of these tight junctions varies with hormone status. That is, with oestrogen treatment, in rats, the junctional strands run more parallel to the apical surface and possess fewer complex intersections than those in ovariectomized animals (Murphy et al., 1981). By contrast, in rats and rabbits, during pregnancy and pseudopregnancy, respectively, a proliferation of tight junctional belts relative to that observed at oestrus occurs, in which the strands multiply and the junction extends more basally (Murphy et al., 1982; Winterhagen \& Kuhnel, 1982). The complexity of the junctional strand intersection has been suggested to be an important factor influencing permeability of the tight junction (Claude \& Goodenough, 1973). Hence the uterine epithelial tight junction may form a more effective rate-limiting boundary under some endocrine conditions more than others. Several ultrastructural studies following intravenously administered horseradish peroxidase $\left(M_{\mathrm{r}} 40000\right.$, ESR $\left.30 \mathrm{~nm}\right)$ to rats demonstrate that the electron-dense reaction products of this enzyme can be visualized in the intercellular spaces of the stroma and between epithelial cells up to the level of the tight junctions, in oestrogen-treated immature animals (Anderson et al., 1975) and during implantation (Parr, 1980). As noted above, vascular permeability under these reproductive conditions is enhanced, thus enabling the extravascular transfer of horseradish peroxidase. These results indicate that the uterine epithelium continues to function as a rate-limiting boundary or barrier between blood and the uterine lumen even under vascular conditions of increased permeability. Furthermore, the blood-uterine lumen barrier is virtually impermeable to such substances as mannitol, sucrose and inulin (McRae \& 
Kennedy, 1983a) and yet the uterine volumes of distribution (i.e. ratio of tissue concentration to plasma concentration) in rats with ligated renal pedicles (see Fig. 1) for such substances are equal to or larger than extracellular fluid volumes in a variety of non-reproductive organs (Larsson et al., 1980). This indicates that whereas the uterine epithelium is markedly impermeable to these substances, the microvascular endothelium and stromal interstitium are not. Thus, for most substances, the primary rate-limiting boundary between blood and the uterine lumen is the epithelium. The microvascular endothelium then acts as an additional barrier principally affecting the transfer of substances with molecular weights possibly greater than 1000-5000.

The permeability properties of the primary rate-limiting boundary between blood and the uterine lumen in rats indicate that this barrier behaves towards blood-borne substances as a lipoid layer interrupted by water-filled channels (Connor \& Miller, 1973; McRae \& Kennedy, 1983a, b). As such, it favours the transfer by passive diffusion of more lipophilic compounds (antipyrine, barbital) over more hydrophilic ones (mannitol, sucrose and inulin). In addition, the transfer across the barrier of lipophilic substances such as antipyrine and barbital is greater in animals treated with oestrogen and progesterone than in animals treated with progesterone alone (McRae \& Kennedy, $1983 b$ ). It is pertinent that a recent freeze-fracture cytochemical study with digitonin has demonstrated that the cholesterol content of the apical plasma membrane of uterine epithelial cells is greater in rats on Day 6 of pregnancy (a primarily progesterone-treated uterus) than on Day 1 (a primarily oestrogen-treated uterus) (Murphy \& Martin, 1985). Altered cholesterol content is likely to change the fluidity of the membrane and might account for the differences in permeability to antipyrine and barbital noted above. Other results indicate that this barrier is selectively permeable to markedly hydrophilic compounds according to molecular size such that mannitol $\left(M_{\mathrm{r}} 182\right.$, ESR $0.42 \mathrm{~nm}$ ) and compounds larger than mannitol are sterically hindered. However, the ability of inulin $\left(M_{\mathrm{r}} 5200\right.$, ESR $\left.1.3 \mathrm{~nm}\right)$ to cross this boundary was similar to that of sucrose $\left(M_{\mathrm{r}} 342\right.$, ESR $0.51 \mathrm{~nm})($ McRae \& Kennedy, 1983a). This discrepancy between molecular sizes and transfer rates for sucrose and inulin has also been observed for transfer of these compounds across cerebral capillaries (Amtorp, 1980) and was interpreted to indicate a non-discriminatory (on the basis of molecular size), transcellular pathway involving pinocytotic vesicles. Thus a similar pathway may be involved in transferring substances (especially those of $M_{\mathrm{r}}>1000$ ) across the uterine epithelium.

The blood-uterine lumen barrier also has the ability to transport a variety of low molecularweight electrolytes and non-electrolytes including potassium (Levin \& Edwards, 1968), amino acids (Walters et al., 1979, 1981), glucose and certain other monosaccharide energy substrates (Leese et al. 1979) and possibly prostaglandins (see below) (Jones \& Harper, 1983; Cao et al., 1984). For example, the potassium ion concentration in uterine fluid from rat pro-oestrous fluid, which accumulates copiously, is about 10 -fold greater than that in plasma (Howard \& DeFeo, 1959). In undiluted samples of human uterine fluid, potassium ion concentration is 4- or 5-fold greater than that in plasma (Casslen \& Nilsson, 1984). Available evidence for bovine (Olds \& VanDemark, 1957; Schultz et al., 1971) and rabbit (Lutwak-Mann, 1962) uterine fluid indicates potassium concentrations in these fluids in excess of their plasma concentrations. An ability of the uterine epithelium in several species to concentrate, presumably actively (Levin \& Edwards, 1968), potassium ion against a steep electrochemical gradient is implied by these findings.

In addition to potassium, the uterine epithelium might also concentrate prostaglandins (PGs) in luminal extracellular fluid. The fluid which accumulates in a non-gravid horn in sheep in response to chronically elevated concentrations of progesterone (Bazer et al., 1979) contains large amounts of PGF in concentrations up to $4000 \mathrm{ng} / \mathrm{ml}$ (Harrison et al., 1976). These considerable concentrations in uterine fluid occur in the absence of comparable concentrations in jugular vein plasma or uterine vein plasma. Furthermore, in pigs, total recoverable PGF in uterine flushings are greater in pregnant than non-pregnant gilts between Days 12 and 18 after oestrus (see Bazer et al., 1986). Moreover, concentrations of PGF- $2 \alpha$ in utero-ovarian vein plasma and PGFM (the stable metabolite of PGF-2 $\alpha$ ) in jugular vein plasma have been reported to be higher during luteolysis in the 
non-pregnant pig than during the equivalent interval in pregnancy (Moeljono et al., 1977). These observations suggest that the uterine epithelium maintains a steep concentration gradient for PGF between luminal and endometrial extracellular fluid during pregnancy. This interpretation is, however, complicated by data from cows (Thatcher et al., 1984): PGF-2 $\alpha$ was infused through the uterine lumen before, during and after PGE-2 was added to the infusate. During the combined PGE-2 and PGF-2 $\alpha$ infusion, the output rates (ng/min) of PGF- $2 \alpha$ and PGFM were elevated in the utero-ovarian vein concurrently with increased uterine blood flow. Uterine blood flow was therefore probably increased as a result of PGE-2-induced vasodilatation and PGF- $2 \alpha$ and PGFM were cleared more rapidly from the uterus as a consequence. This greater clearance rate would probably result in lower concentrations $(\mathrm{ng} / \mathrm{ml})$ of PGF- $2 \alpha$ and PGFM in venous plasma. In the pig it is notable that there is a sharp peak of blood flow on Days 12 and 13 after mating (see Ford \& Stice, 1985), a time which coincides with elevated concentrations of PGF in luminal extracellular fluid. Therefore, rapid clearance of PGF from endometrial extracellular fluid might account, at least in part, for the apparent concentration gradient between extracellular fluids, and precise quantification of endometrial extracellular fluid concentrations will be required to determine whether an effective concentration gradient exists between uterine extracellular fluids in the pig during early pregnancy.

Studies of the distribution of prostaglandins in red blood cells indicate that these compounds are largely unable to diffuse passively across plasma membranes at physiological $\mathrm{pH}$ (Bito, 1975). However, PGF-2 $\alpha$ infused into the uterine lumina of pregnant and non-pregnant cows was associated with marked elevations of PGFM in jugular plasma by $20 \mathrm{~min}$ after initiation of infusion (Thatcher et al., 1984). Clearly then, prostaglandins are able to cross the blood-uterine lumen barrier in cows. Although these compounds are relatively small in size, and lipophilic by nature in their undissociated forms, they are more than $90 \%$ dissociated at physiological pH (Jones \& Harper, 1983). Therefore, they are unlikely to diffuse freely across plasma membranes in vivo, due to the greater hydrophilicity of the dissociated molecular form. As a result, transport of prostaglandins across uterine plasma membranes is likely to require a carrier mechanism. In-vitro studies of prostaglandin uptake by uterine epithelial cell plaques from rabbits (Jones \& Harper, 1983) and by endometrial cells from cows (Thatcher et al., 1984) suggest that these tissues are able to concentrate prostaglandins intracellularly (i.e. ratios of tissue to medium concentrations, corrected for extracellular fluid volumes, greater than 1.0). In both studies, however, no evidence was found that the transport mechanisms were saturable at the concentrations tested. Therefore, available evidence indicates that uterine plasma membranes transport prostaglandins although the mechanisms and their kinetics are poorly understood.

Transfer across the uterine epithelium includes high molecular weight substances such as proteins. This is evident from serum proteins in uterine flushings from all species studied, usually in amounts greater than those of uterine-specific proteins (see McRae, 1984). Furthermore, several proteins $\left(\alpha_{1}\right.$-antitrypsin and $\alpha_{1}$-antichymotrypsin), probably of serum origin, are present in both human endometrial extracellular fluid (Tauber et al., 1985) and luminal extracellular fluid (Casslen, 1986). The tight junctions joining adjacent epithelial cells are impermeable to proteins such as horseradish peroxidase (see above), therefore proteins in general are not thought to diffuse freely into luminal extracellular fluid via an intercellular pathway. Instead a transcellular pathway involving pinocytotic vesicles has been suggested (Parr, 1980; McRae \& Kennedy, 1983a) to account for serum proteins in uterine fluid. This hypothesis is supported by observations that, after intravenous administration of horseradish peroxidase, reaction product is observed within invaginations of the basolateral membrane of uterine epithelial cells and within vesicles located in the apical portions of these walls (Anderson et al., 1975; Parr, 1980). Furthermore, horseradish peroxidase reaction product can be visualized in cytoplasmic vesicles in uterine glandular epithelium by 1 min after intravenous administration (Castillo-Jessen \& Gonzalez-Angulo, 1973). Also, the protein content of uterine flushings (Surani, 1975, 1976) is correlated with the incidence of basolateral pinocytotic invaginations in epithelial cells (Parr, 1980, 1982). There is thus suggestive evidence that high 
molecular weight substances present in endometrial extracellular fluid can be transported across the uterine epithelium by a transcellular pathway.

Recent studies of the secretory immune system of the uterus provide notable examples of the transfer of proteins from endometrial to luminal extracellular fluids. Firstly, a rapid, oestrogeninduced influx of serum IgG and total protein into uterine fluid was observed and was found to peak at $3 \mathrm{~h}$ then decline markedly by $6 \mathrm{~h}$ after oestradiol (Sullivan $\&$ Wira, 1983). Uterine tissue content of IgG and cytosol protein also increased after oestradiol treatment, peaking at $6 \mathrm{~h}$. Oestrogen-induced increased vascular permeability (see above) probably accounts for the elevated concentrations of tissue protein including IgG. It is unlikely, however, that the elevated concentrations of protein in luminal fluid are the simple consequence of enhanced transfer of plasma protein into extravascular extracellular fluid. This is because increased amounts of IgG in endometrial extracellular fluid in mice in association with blastocyst-induced increased vascular permeability were not accompanied by an influx into luminal extracellular fluid (Rachman et al., 1986). Thus, the oestrogen-induced influx of plasma proteins into luminal extracellular fluid could result from a transient opening of the epithelial tight junctions. Alternatively, oestrogen might stimulate the activity of a transcellular pinocytotic pathway across uterine epithelium.

In contrast to IgG, IgA does not appear in luminal extracellular fluid in response to oestrogen treatment in appreciable amounts until $25 \mathrm{~h}$ after a second oestrogen injection given $24 \mathrm{~h}$ after the first. By $6 \mathrm{~h}$ after a third injection of oestrogen, $\operatorname{IgA}$ concentrations in uterine fluid are apparently far in excess of those in endometrial extracellular fluid. This suggests that $\operatorname{IgA}$ is accumulating in the uterine lumen against a steep concentration gradient. By comparison, amounts of IgG in luminal extracellular fluid under this hormone regimen are likely to be a small fraction of those in endometrial extracellular fluid (Sullivan \& Wira, 1984). IgA accumulated in response to prooestrous oestrogen is apparently lost from the uterine lumen of cyclic rats when uterine fluid is discharged, via the vagina at oestrus (Sullivan \& Wira, 1984), and as such is not reabsorbed by the uterine epithelium. The source of IgA which is transported into the luminal extracellular fluid is most likely that produced locally by plasma cells since experimentally elevated concentrations of serum IgA were not reflected by luminal levels (Wira \& Stern, 1986). Available evidence indicates that $\operatorname{IgA}$, polymeric form only, is transported specifically from endometrial to luminal extracellular fluid (Sullivan \& Wira, 1981, 1984). This transport probably involves synthesis by epithelial cells of a glycoprotein, referred to as secretory component, which acts as a basolateral cell-surface receptor for $\operatorname{IgA}$. IgA binds to secretory component then is internalized by endocytosis. As a complex with secretory component, $\operatorname{IgA}$ is transported across the epithelial cell then the complex is released into luminal extracellular fluid. In rats the $\operatorname{IgA}$ present in this fluid is bound to secretory component (Sullivan \& Wira, 1981). Oestrogens appear to be principal regulators of IgA plasma cells to the uterus and upon uterine levels of secretory component (Sullivan \& Wira, 1981). Thus, the transfer of $\mathrm{IgA}$ and $\mathrm{IgG}$ across the uterine epithelium in response to oestrogen occurs by two distinct mechanisms, one of which (IgA) is specific and likely to require protein synthesis (Wira et al., 1984) and the other $(\mathrm{IgG})$ is non-specific and accompanied by a general influx of protein, probably of plasma origin.

The specificity of the IgA transport mechanism probably enables this immunoglobulin to accumulate in luminal extracellular fluid at concentrations in excess of those in endometrial extracellular fluid. Some other serum proteins apparently accumulate in luminal extracellular fluid since their contributions to total protein content in luminal fluid are disproportionately greater than in serum (Hall et al., 1977; Surani, 1977). The presence of cell-surface receptors, formation and internalization of coated pits and translocation of coated vesicles are likely to confer specificity, thus facilitating differential transfer of these proteins.

Currently available evidence therefore suggests that the blood-uterine lumen barrier is endowed with the ability to transfer selectively a range of substances with the consequence that concentrations of some substances can differ markedly among luminal, endometrial and vascular extracellular fluids. 


\section{Uptake and release by endometrial and embryonic cells}

The extracellular fluid compartments of the lumen and endometrium are influenced by the uptake and release of materials into and out of the intracellular compartments of the endometrium (including epithelial). Available evidence indicates that uterine endometrium synthesizes and secretes a variety of proteins although in the absence of histochemical localization it is not always clear whether epithelial and/or stromal cells are primarily responsible. Nevertheless, it appears that the majority of uterine-specific secretory products synthesized by the luminal and glandular epithelium are secreted into the luminal extracellular fluid. Endometrial stromal cells appear to remove extravasated material from endometrial extracellular fluid. Various migratory cells are interspersed in the endometrial interstitium and contribute to the extracellular fluid. Lastly, considerable evidence indicates that the developing embryo in many species elaborates and secretes a variety of compounds which are likely to act primarily upon maternal reproductive functions.

Uterine epithelial cells possess abundant Golgi apparatus and polyribosomes, well-developed and dilated rough endoplasmic reticulum and accumulated secretory granules or vacuoles in the apical region, all of which are suggestive of protein synthesis and secretion (Jamieson \& Palade, 1971). These cells synthesize and secrete a variety of proteins (see Roberts \& Bazer, 1988, for review), many, but not all, of which are enzymically active. For example, lysosome-like enzymic activities which resemble that of $\beta-N$-acetylglucosaminidase have been observed in luminal extracellular fluid of pigs, mares and ewes (Hansen et al., 1985) and rabbits (Thie et al., 1984, 1986). In the uterine fluid of rabbits, enzymic activities resembling that of $\alpha$-1-fucosidase have also been observed (Thie et al., 1984, 1986). Several antiproteolytic enzymes have also been demonstrated, including a plasminogen activator inhibitor in western spotted skunk (Fazleabas et al., 1984) and proteinase inhibitor in pig (Fazleabas et al., 1985). Proteins without apparent enzymic activity such as prolactin (Stone et al., 1986; Ying et al., 1986) and relaxin (Larkin \& Renegar, 1986) are also synthesized and secreted. Available evidence indicates that the majority of these uterine-specific secretory products are released into luminal extracellular fluid as opposed to endometrial extracellular fluid.

Proteins which appear to be exceptions to the rule that epithelial secretory proteins are released primarily into luminal extracellular fluid include human pregnancy-associated plasma protein-A and a prolactin-inhibitory factor in rats. Pregnancy-associated plasma protein-A is found in uterine fluid and plasma and can be detected in glandular epithelial cells during the proliferative phase of the menstrual cycle (Bischof et al., 1984). A prolactin-inhibitory factor in rats is synthesized in the uterine epithelium and appears to inhibit prolactin release from the anterior pituitary in vivo (Goropse \& Freeman, 1985). It therefore appears that secretion of proteins synthesized by epithelial cells can occur across either the apical or basolateral cell membranes. Therefore, cellular mechanisms probably function to direct specific products towards the apical or the basolateral membranes.

The uterine stroma is composed of a network of stromal cells which make contact with several adjacent cells by means of slender cytoplasmic processes (Ljungkvist, 1971; Rogers \& Wischik, 1983). Embedded within this network are the bases of endometrial glands, blood vessels and lymphatic vessels. The lymphatic vessels appear to be small and sparsely distributed in virgin rats (Head \& Seelig, 1984) and increase in diameter during pregnancy (see Head \& Billingham, 1986). Recent observations indicate that stromal cells are capable of actively internalizing material from the endometrial extracellular fluid by means of numerous plasmalemmal-coated pits (Cornillie $\&$ Lauweryns, 1985). This uptake occurred either specifically into receptosomes via clathrin-coated pits and tubulovesicular organelles or less specifically via the formation of macropinocytotic vacuoles. In addition, differentiation of phagocytes from endometrial stromal cells was described. 
These phagocytotic cells appeared to accumulate ferritin and other stromal glycoproteins to result in a considerable storage of iron, in the form of haemosiderin complexes. They also appeared to occupy a primarily perivascular location in the superficial endometrium. These cells are thought to compensate for the absence of a well-developed lymphatic drainage (Cornillie \& Lauweryns, 1985). Thus, stromal cells are capable of modifying the endometrial extracellular fluid which surrounds them by actively removing materials via specific and non-specific internalization processes.

The endometrial interstitium is also interspersed with various migratory cells, including neutrophils, macrophages, lymphocytes and occasionally mast cells (Brandon \& Evans, 1984; Head \& Gaede, 1986). Of these, neutrophils, lymphocytes and mast cells release substances which modify the endometrial extracellular fluid. For example, much of the peroxidase activity detected in the uterus, excluding epithelium, is derived from eosinophils (Tchernitchen et al., 1976). Similarly, IgA and IgG are released into endometrial extracellular fluid from IgA-positive and IgG-positive lymphoid cells which migrate in the uterus in response to oestrogen (Wira et al., 1980; Parr, M. B. \& Parr, E. L., 1986). These plasma cells are reported to be localized predominantly near the glands of the endometrium (Parr, E. L. \& Parr, M. B., 1986). Furthermore, IgA-positive cells were apparently predominant, although IgG-positive cells were difficult to discern due to heavy immunostaining of interstitial IgG. In addition, the vasoactive mediator histamine is released from mast cells under appropriate conditions. In contrast the release of material, uptake of cellular debris and perhaps soluble material by phagocytotic activities of macrophages (Head \& Gaede, 1986) are also highly likely. The intracellular compartments of the non-stromal endometrial cells therefore also have the ability to modify the composition of endometrial extracellular fluid.

The developing conceptus in many species produces proteins, steroids and prostaglandins which are likely to function in maternal recognition of pregnancy, immunological privilege of the conceptus, the induction of histotrophe in domestic animals and possibly further progestational differentiation of the endometrium. The potential mechanisms and structures for transfer of proteins across the blood-uterine lumen barrier will be discussed briefly, whereas those for steroid and prostaglandins have been reviewed elsewhere (see above and McRae, 1984). Sheep and cattle conceptuses (see Bazer et al., 1986) are thought to produce specific proteins which are taken up by the surface and upper gland epithelial cells but do not seem to enter the maternal circulation. In sheep and cattle these proteins, ovine and bovine trophoblast protein I, share partial structural homology and are thought to act locally within the uterus to inhibit the abilities of oestradiol and oxytocin to induce uterine production of PGF, thus inhibiting luteolysis. These proteins could either act directly in the process or could stimulate production of one or more proteins locally in the endometrium. Uptake of proteins from the luminal extracellular fluid into uterine epithelial cells has been investigated in cows in which horseradish peroxidase was administered into the uterine lumen (Guillomot et al., 1986). By $20 \mathrm{~min}$ after administration, reaction product was especially evident within cytoplasmic vesicles immediately below the base of the microvillous border of the cells. Some ingested material was apparent in lysosome-like bodies, whereas tracer-containing vesicles which had fused with the lateral membranes of the cells were also observed. Furthermore, reaction product was observed in the intercellular spaces up to the tight junctions and beneath the basal membrane. Endocytotic uptake of horseradish peroxidase is thought to represent 'fluid-phase' uptake of soluble material (i.e. material which does not adsorb initially to the plasma membrane) (Morales \& Hermo, 1983). Thus, endocytosis of this type has been suggested to participate in the reabsorption of uterine fluid from the lumen (Enders \& Nelson, 1973; Parr \& Parr, 1974, 1977). However, because mannose-specific binding sites for horseradish peroxidase have been described for various cells in the rat (Straus, 1983; Wilson \& King, 1986), internalization of this protein might be more specific than previously considered. Nevertheless, these observations demonstrate a transcellular pathway through which proteins synthesized and secreted by the conceptus, such as ovine and bovine trophoblast protein I, might be transferred from the luminal to endometrial extracellular fluid. Secretory products of the developing conceptus are therefore capable of 
modifying the nature of the luminal extracellular fluid. Whether these products also modify endometrial extracellular fluid is uncertain. However, sheep trophoblast proteins have not been found in maternal plasma in measurable amounts (Godkin et al., 1984; Manns \& Lewing, 1986).

A rate-limiting boundary between luminal and endometrial extracellular fluids has been demonstrated. This barrier is likely to maintain concentrations of uterine-specific proteins in these fluids at appropriate levels more effectively than in the absence of such a barrier. Furthermore, as noted above, a large majority of the proteins partly characterized in luminal extracellular fluid, of uterine and embryonic origin, have proteolytic and lysosyme-like activity or have antiproteolytic activity. Because of these enzymic activities, uncontrolled leakage of these proteins into the endometrial extracellular fluid compartment could have profoundly detrimental effects upon the integrity of the stromal tissue. Thus, the blood-uterine lumen barrier is likely to play an important role in enhancing the efficacy of uterine secretions and protecting adjacent compartments from these secretions.

\section{Luminal extracellular fluid and embryo development}

Blastocyst differentiation requires factors extrinsic to the embryo; this requirement exemplifies the influence of the uterine luminal milieu upon embryonic development. Relatively simple culture media containing salts, amino acids, serum albumin and an energy source are sufficient for the successful in-vitro development of 2-cell mouse embryos to the hatched blastocyst stage. By contrast even relatively complex defined media (e.g. NCTC-109) are unable to promote blastocyst development in vitro (Rizzino \& Sherman, 1979; Sellens \& Sherman, 1980). Differentiation in vitro of the trophectoderm and inner cell mass requires the addition of serum (Cole \& Paul, 1965; Gwatkin, 1966; Spindle \& Pedersen, 1974; Spindle \& Goldstein, 1975) or serum-derived, high molecular-weight protein fractions (fetuin) (Rizzino \& Sherman, 1979; Hsu, 1979; Sellens \& Sherman, 1980). The ability of serum to induce further differentiation is probably due to the presence of particular growth-promoting factors. It is pertinent that insulin-binding activity by mouse embryos which is stage-specific has been observed (Rosenblum et al., 1986). However, whether this binding activity represents functional receptors for insulin is not clear. Nevertheless, the presence of these binding sites is consistent with enhancement of embryo development in utero by blood-borne growth factors such as insulin or insulin-like growth factor. Presumably this requirement of blastocyst differentiation in vitro for extrinsic factors is fulfilled in utero by growthpromoting factors present in luminal extracellular fluid. The nature of this fluid therefore affects blastocyst growth and differentiation.

\section{Conclusions}

The extracellular fluids of the uterus, i.e. vascular, endometrial and luminal fluids, are separated by dynamically active boundaries. Collectively, these boundaries are referred to as the blood-uterine lumen barrier. An important consequence of this barrier is that marked compositional differences between these fluids might be created and maintained. Thus, a unique fluid which is specialized to fulfil the nutritional and informational requirements for successful differentiation might form the luminal milieu of the developing conceptus. Considerable evidence indicates that the rate-limiting boundaries of the uterus have the capacity to create and maintain specialized extracellular fluids by virtue of their permeability and transport properties.

The Alberta Heritage Foundation for Medical Research is acknowledged for its financial support. I thank M. R. Cudmore, Ashdon Computer Services and Gloria Schneider for assistance. 


\section{References}

Abrahamsohn, P., Lundkvist, O. \& Nilsson, O. (1983) Ultrastructure of the endometrial blood vessels during implantation of the rat blastocyst. Cell Tiss. Res. 229, 269-280.

Amtorp, O. (1980) Estimation of capillary permeability of inulin, sucrose and mannitol in rat brain cortex. Acta physiol. scand. 110, 337-342.

Anderson, W.A., Kang, Y-H. \& Desombre, E.R. (1975) Endogenous peroxidase: specific marker enzyme for tissue, displaying growth dependency on estrogen. $J$. Cell Biol. 64, 668-681.

Bazer, F.W., Thatcher, W.W., Roberts, R.M., Basha, S.M.M., Zavy, M.T., Caton, D. \& Barron, D.H. (1979) Method for obtaining ovine uterine secretions from unilaterally pregnant ewes. J. Anim. Sci. 49, 1522-1527.

Bazer, F.W., Vallet, J.L., Roberts, R.M., Sharp, D.C. \& Thatcher, W.W. (1986) Role of conceptus secretory products in establishment of pregnancy. J. Reprod. Fert. 76, 841-850.

Bischof, P., Schindler, A.M., Urner, F., Mensi, N., Herrmann, W.L. \& Sizonenko, P.C. (1984) Pregnancy-associated plasma protein-A (PAPP-A): concentration in uterine fluid and immunohistochemical localization in the endometrium. Br. J. Obstet. Gynaecol. 91, 863-869.

Bito, L.Z. (1975) Are prostaglandins intracellular, transcellular or extracellular autocoids? Prostaglandins 9, 851-855.

Brandon, J.M. \& Evans, J.E. (1984) Observations on uterine mast cells during early pregnancy in the vole, Microtus agrestis. Anat. Rec. 208, 515-520.

Cao, Z-D., Jones, M.A. \& Harper, M.J.K. (1984) Prostaglandin translocation from the lumen of the rabbit uterus in vitro in relation to day of pregnancy or pseudopregnancy. Biol. Reprod. 31, 505-519.

Casslen, B. (1986) Inhibitors of trypsin, chymotrypsin and elastase in human uterine fluid. Acta obstet. gynaec. scand. 65, 121-124.

Casslen, B. \& Nilsson, B. (1984) Human uterine fluid, examined in undiluted samples for osmolarity and the concentration of inorganic ions, albumin, glucose and urea. Am. J. Obstet. Gynecol. 150, 877-881.

Castillo-Jessen, M.C. \& Gonzalez-Angulo, A. (1973) Permeability of endometrial blood vessels to exogenous peroxidase in mice: an electron microscope study. In Electron Microscopic Concepts of Secretion, pp. 113-128. Ed. M. Hess. John Wiley and Sons, New York.

Claude, P. \& Goodenough, D.A. (1973) Fracture faces of zonulae occludentes from 'tight' and 'leaky' epithelia. J. Cell Biol. 58, 390-400.

Cole, R.J. \& Paul, J. (1965) Properties of cultured preimplantation mouse and rabbit embryos, and cell strains derived from them. In Preimplantation Stages of Pregnancy (Ciba Fdn Symp. No. 60), pp. 82-122. Eds G. E. W. Wolstenholme \& M. O'Connor. J. and A. Churchill, London.

Connor, E.A. \& Miller, J.W. (1973) The distribution of selected substances into rat uterine luminal fluid. $J$. Pharmac. exp. Ther. 184, 291-298.
Cornillie, F.J. \& Lauweryns, J.M. (1985) Phagocytotic and iron-storing capacities of stromal cells in the rat endometrium. Cell Tissue Res. 239, 467-476.

Davson, H. (1955) A comparative study of the aqueous humour and cerebrospinal fluid in the rabbit. $J$. Physiol., Lond. 129, 111-113.

Dewey, W.C. (1959) Vascular-extravascular exchange of $\mathrm{I}^{131}$ plasma proteins in the rat. Am. J. Physiol. 197, 423-431.

Dvorak, H.F., Senger, D.R., Dvorak, A.M., Harvey, V.S. \& McDonagh, J. (1985) Regulation of extravascular coagulation by microvascular permeability. Science, N.Y. 227, 1059-1061.

Enders, A.C. \& Nelson, D.M. (1973) Pinocytotic activity of the uterus of the rat. Am. J. Anat. 138, 277-300.

Fazleabas, A.T., Mead, R.A., Rourke, A.W. \& Roberts, R.M. (1984) Presence of an inhibitor of plasminogen activator in uterine fluid of the western spotted skunk during delayed implantation. Biol. Reprod. 30, 311-322.

Fazleabas, A.T., Bazer, F.W., Hansen, P.J., Geisert, R.D. \& Roberts, R.M. (1985) Differential patterns of secretory protein localization within the pig uterine endometrium. Endocrinology 116, 240-245.

Finlay, T.H., Katz, J., Rasums, A., Seiler, S. \& Levitz, M. (1981) Estrogen-stimulated uptake of $\alpha_{1}$-protease inhibitor and other plasma proteins by the mouse uterus. Endocrinology 108, 2129-2136.

Ford, S.P. \& Stice, S.L. (1985) Effects of ovary and conceptus on controlling uterine blood flow in the pig. $J$. Reprod. Fert., Suppl. 33, 83-90.

Frederick, G.T., Kirkland, J.L., Stancel, G.M. \& Gardner, R.M. (1985) Effects of experimentallyinduced diabetes on oestradiol-stimulated changes in the ultrastructure of the rat endometrium. Acta endocr., Copenh. 108, 414-420.

Godkin, J.D., Bazer, F.W. \& Roberts, R.M. (1984) Ovine trophoblast protein I, an early secreted blastocyst protein, binds specifically to uterine endometrium and affects protein synthesis. Endocrinology 114, $120-130$.

Gorospe, W.C. \& Freeman, M.E. (1985) Detection of prolactin inhibitory activity in uterine epithelial cell secretions and rat serum. Endocrinology 116, 1559-1564.

Guillomot, M., Betteridge, K.J., Harvey, D. \& Goff, A.K. (1986) Endocytotic activity in the endometrium during conceptus attachment in the cow. J. Reprod. Fert. 78, 27-36.

Gwatkin, R.B.L. (1966) Amino acid requirements for attachment and outgrowth of the mouse blastocyst in vitro. J. Cell Physiol. 68, 335-344.

Hall, J.L., Stephenson, R.B., Mathias, C.A. \& Brackett, B.G. (1977) Hormonal dependence of cyclic patterns in hamster uterine fluid proteins. Biol. Reprod. 17, 738-744.

Ham, K.N., Hurley, J.V., Lopata, A. \& Ryan, G.B. (1970) A combined isotopic and electron microscope study of the response of the rat uterus to exogenous oestradiol. J. Endocr. 46, 71-81.

Handley, D.A. \& Chien, S. (1987) Colloidal gold labeling studies related to vascular and endothelial function, 
hemostasis and receptor-mediated processing of plasma macromolecules. Eur. J. Cell Biol. 43, 163-174.

Hansen, P.J., Bazer, F.W. \& Roberts, R.M. (1985) Appearance of $\beta$-hexosaminidase and other lysosomal-like enzymes in the uterine lumen of gilts, ewes and mares in response to progesterone and oestrogens. J. Reprod. Fert. 73, 411-424.

Harrison, F.A., Heap, R.B. \& Poyser, N.L. (1976) Production, chemical composition and prostaglandin F-2 $\alpha$ content of uterine fluid in pregnant sheep. J. Reprod. Fert. 48, 61-67.

Harvey, C.A. \& Owen, D.A.A. (1976) Changes in uterine and ovarian blood flow during the oestrous cycle in rats. J. Endocr. 71, 367-369.

Head, J.R. \& Billingham, R.E. (1986) Concerning the immunology of the uterus. Am. J. Reprod. Immunol. Microbiol. 10, 76-81.

Head, J.R. \& Gaede, S.D. (1986) Ia antigen expression in the rat uterus. J. Reprod. Immunol. 9, 137-153.

Head, J.R. \& Seelig, L.L., Jr (1984) Lymphatic vessels in the uterine endometrium of virgin rats. J. Reprod. Immun. 6, 157-166.

Hechter, O., Krohn, L. \& Harris, J. (1942) Effects of estrogens and other steroids on capillary permeability. Endocrinology 30, 598-608.

Hofmann, G.E., Rao, Ch.V., Barrows, G.H., Schultz, G.S. \& Sanfilippo, J.S. (1984) Binding sites for epidermal growth factor in human uterine tissues and leiomyomas. J. clin. Endocr. Metab. 58, 880-884.

Hormia, M. \& Virtanen, I. (1986) Endothelium - an organized monolayer of highly specialized cells. Med. Biol. 64, 247-266.

Howard, E. \& DeFeo, V.J. (1959) Potassium and sodium content of uterine and seminal vesicle secretions. $\mathrm{Am}$. J. Physiol. 196, 65-68.

Hsu, Y-C. (1979) In vitro development of individually cultured whole mouse embryos from blastocyst to early somite stage. Devl Biol. 68, 453-461.

Jamieson, J.D. \& Palade, G.E. (1971) Synthesis, intracellular transport, and discharge of secretory proteins in stimulated pancreatic exocrine glands. J. Cell Biol. 50, 135-158.

Jones, M.A. \& Harper, M.J.K. (1983) Prostaglandin accumulation by isolated uterine endometrial epithelial cells from six-day pregnant rabbits. Biol. Reprod. 29, 1201-1209.

Joris, I., Majno, G., Corey, E.J. \& Lewis, R.A. (1987) The mechanism of vascular leakage induced by leukotriene E4. Am. J. Pathol. 126, 19-24.

Kalman, S.M., Lombrozo, M.E. \& Lavis, V. (1961) Effect of estradiol on the transfer rate of small molecules into the rat uterus. Science, N.Y. 134, 1372-1373.

Keyes, J.L., King, G.J. \& Kennedy, T.G. (1986) Increased uterine vascular permeability at the time of embryonic attachment in the pig. Biol. Reprod. 34, 405-411.

Kulangara, A.C. (1976) Maintenance of plasma-derived proteins at much lower concentrations in the uterine lumen of the rabbit. Kinetic study of passage. $J$. Reprod. Fert. 46, 189-194.

Larkin, L.H. \& Renegar, R.H. (1986) Immunochemical and cytochemical studies of relaxin-containing cells in the guinea pig uterus. Am. J. Anat. 176, 353-365.

Larsson, M., Johnson, L., Nylander, G. \& Ohman, U. (1980) Plasma water and 51CrEDTA equilibration volumes of different tissues in the rat. Acta physiol. scand. 110, 53-57.

Leese, H.J., Aldridge, S. \& Kiernan, T. (1979) Glucose movement into rat uterine fluid. J. Reprod. Fert. 56, 615-618.

Levin, R.J. \& Edwards, F. (1968) The transuterine endometrial potential difference, its variation during the oestrous cycle and its relation to uterine secretion. Life Sci. 7, 1019-1036.

Ljungkvist, I. (1971) Attachment reaction of the rat uterine luminal epithelium. I. Gross and fine structure of the endometrium of the spayed virgin rat. Acta Soc. Med. Ups. 76, 91-109.

Lutwak-Mann, C. (1962) Some properties of uterine and cervical fluid in the rabbit. Biochim. biophys. Acta 58, 637-639.

Manns, J.G. \& Lewing, P.J. (1986) Protein production by sheep embryos during the period of maternal recognition of pregnancy. Can.J. Physiol. Pharmacol. 64, 1223-1228.

Marley, P.B. \& Robson, J.M. (1971) Passage of sodium into the uterine lumen of the rat during the sexual cycle and under the influence of steroidal hormones. $J$. Reprod. Fert. 26, 879-887.

Martin, L., Hallowes, R.C., Finn, C.A. \& West, C.G. (1973) Involvement of the uterine blood vessels in the refractory state of the uterine stroma which follows oestrogen stimulation in progesterone-treated mice. $J$. Endocr. 56, 309-314.

McLachlan, J.A., Dames, N.M., Sieber, S.M. \& Fabro, S. (1976) Accumulation of nicotine in the uterine fluid of the six-day pregnant rabbit. Fert. Steril. 27, 1204-1213.

McRae, A.C. (1984) The blood-uterine lumen barrier and its possible significance in early embryo development. Oxford Rev. Reprod. Biol. 6, 129-173.

McRae, A.C. \& Kennedy, T.G. (1979) Evidence for a permeability barrier between blood and uterine luminal fluid in estrogen-treated, immature rats. Biol. Reprod. 20, 919-923.

McRae, A.C. \& Kennedy, T.G. (1983a) Selective permeability of the blood-uterine lumen barrier in rats: importance of molecular size. Biol. Reprod. 29, $879-885$

McRae, A.C. \& Kennedy, T.G. (1983b) Selective permeability of the blood-uterine lumen barrier in rats: importance of lipid solubility. Biol. Reprod. 29, 886-894.

Moeljono, M.P.E., Thatcher, W.W., Bazer, F.W., Frank, M., Owens, L.J. \& Wilcox, C.J. (1977) A study of prostaglandin as the luteolysin in swine, II. Characterization and comparison of prostaglandin F, estrogens and progestin concentrations in utero-ovarian vein plasma of nonpregnant and pregnant gilts. Prostaglandins 14, 543-555.

Morales, C. \& Hermo, L. (1983) Demonstration of fluidphase endocytosis in epithelial cells of the male reproductive system by means of horseradish peroxidase-colloidal gold complex. Cell Tiss. Res. 230, 503-510.

Mukku, V.R. \& Stancel, G.M. (1985) Receptors for epidermal growth factor in the rat uterus. Endocrinology 117, 149-154.

Murphy, C.R. \& Martin, B. (1985) Cholesterol in the plasma membrane of uterine epithelial cells: a 
freeze-fracture cytochemical study with digitonin. $J$. Cell Sci. 78, 163-172.

Murphy, C.R., Swift, J.G., Mukherjee, T.M. \& Rogers, A.W. (1981) Effects of ovarian hormones on cell membranes in the rat uterus. II. Freeze-fracture studies on tight junctions of the lateral plasma membrane of the luminal epithelium. Cell Biophysics 3, 5769.

Murphy, C.R., Swift, J.G., Mukherjee, T.M. \& Rogers, A.W. (1982) The structure of tight junctions between uterine epithelial cells at different stages of pregnancy in the rat. Cell Tissue Res. 223, 281-286.

Olds, D. \& VanDemark, N.L. (1957) Composition of luminal fluids in bovine female genitalia. Fert. Steril. 8, 345-354.

Parr, E.L. \& Parr, M.B. (1986) Uptake of immunoglobulins and other proteins from serum into epithelial cells of the mouse uterus and oviduct. $J$. Reprod. Immunol. 9, 339-354.

Parr, M.B. (1980) Endocytosis at the basal and lateral membranes of rat uterine epithelial cells during early pregnancy. J. Reprod. Fert. 60, 95-99.

Parr, M.B. (1982) Effects of ovarian hormones on endocytosis at the basal membranes of rat uterine epithelial cells. Biol. Reprod. 26, 909-913.

Parr, M.B. \& Parr, E.L. (1974) Uterine luminal epithelium: Protrusions mediate endocytosis, not apocrine secretion, in the rat. Biol. Reprod. 11, 220-233.

Parr, M.B. \& Parr, E.L. (1977) Endocytosis in the uterine epithelium of the mouse. J. Reprod. Fert. 50, 151-153.

Parr, M.B. \& Parr, E.L. (1986) Effects of oestradiol-17 $\beta$ and progesterone on the number of plasma cells in uteri of ovariectomized mice. J. Reprod. Fert. 77, 91-97.

Pino, R.M. (1985) Restriction of endogenous plasma proteins by a fenestrated capillary endothelium: an ultrastructural immunocytochemical study of the choriocapillary endothelium. Am. J. Anat. 172, 279-289.

Psychoyos, A. (1973) Endocrine control of egg implantation. In Handbook of Physiology, Section 7, Vol. II, Part 2, pp. 187-251. Eds R. O. Greep, E. G. Astwood \& S. R. Geiger. Am. Physiol. Soc., Washington, D.C.

Rachman, F., Casimiri, V., Psychoyos, A. \& Bernard, O. (1986) Influence of the embryo on the distribution of maternal immunoglobulins in the mouse uterus. $J$. Reprod. Fert. 77, 257-264.

Rizzino, A. \& Sherman, J.I. (1979) Development and differentiation of mouse blastocysts in serum-free medium. Expl Cell Res. 121, 221-233.

Roberts, R.M. \& Bazer, F.W. (1988) The functions of uterine secretions. J. Reprod. Fert. 82, 875-892.

Rogers, A.W. \& Wischik, C.M. (1983) Cell organization in the stroma of the rat uterus. II. Responses to progesterone in the ovariectomised rat. J. Anat. 137, 541553.

Rosenblum, I.Y., Mattson, B.A. \& Heyner, S. (1986) Stage-specific insulin binding in mouse preimplantation embryos. Devl Biol. 116, 261-263.

Schultz, R.H., Fahning, M.L. \& Graham, E.F. (1971) A chemical study of uterine fluid and blood serum of normal cows during the oestrous cycle. J. Reprod. Fert. 27, 355-367.

Sellens, M.H. \& Sherman, M.I. (1980) Effects of culture conditions on the developmental programme of mouse blastocysts. J. Embryol. exp. Morph. 56, 1-22.

Setchell, B.P., VogImayr, J.K. \& Waites, G.M.H. (1969) A blood-testis barrier restricting passage from blood into rete testis fluid but not into lymph. J. Physiol., Lond. 200, 73-85.

Sheets, E.E., Tsibris, C.M., Cook, N.I., Virgin, S.D., DeMay, R.M. \& Spellacy, W.N. (1985) In vitro binding of insulin and epidermal growth factor to human endometrium and endocervix. Am. J. Obstet. Gynaecol. 153, 60-65.

Simionescu, N. (1979) The microvascular endothelium segmental differentiations; transcytosis; selective distribution of anionic sites. Adv. Inflamm. Res. 1, 61-70.

Spindle, A.I. \& Goldstein, L.S. (1975) Induced ovulation in mature mice and developmental capacity of the embryos in vitro. J. Reprod. Fert. 44, 113-116.

Spindle, A.I. \& Pederson, R.A. (1974) Hatching, attachment, and outgrowth of mouse blastocysts in vitro: fixed nitrogen requirements. J. exp. Zool. 186, 305-318.

Stone, B.A., Petrucco, O.M., Seamark, R.F. \& Godfrey, B.M. (1986) Concentrations of steroid hormones, and of prolactin, in washings of the human uterus during the menstrual cycle. J. Reprod. Fert. 78, 21-25.

Straus, W. (1983) Mannose-specific binding sites for horseradish peroxidase in various cells of the rat. $J$. Histochem. Cytochem. 31, 78-84.

Sullivan, D.A. \& Wira, C.R. (1981) Estradiol regulation of secretory component in the female reproductive tract. J. Steroid Biochem. 15, 439-444.

Sullivan, D.A. \& Wira, C.R. (1983) Hormonal regulation of immunoglobulins in the rat uterus: uterine response to a single estradiol treatment. Endocrinology 112, $260-268$.

Sullivan, D.A. \& Wira, C.R. (1984) Hormonal regulation of immunoglobulins in the rat uterus: uterine response to a multiple estradiol treatments. Endocrinology 114, $650-658$.

Surani, M.A.H. (1975) Hormonal regulation of proteins in the uterine secretion of ovariectomized rats and the implications for implantation and embryonic diapause. J. Reprod. Fert. 43, 411-417.

Surani, M.A.H. (1976) Uterine luminal proteins at the time of implantation in rats. J. Reprod. Fert. 48, 141-145.

Surani, M.A.H. (1977) Qualitative and quantitative examination of the proteins of rat uterine luminal fluid during pro-oestrus and pregnancy and comparison with those of serum. J. Reprod. Fert. 50, 281-287.

Szego, C.M. \& Roberts, S. (1953) Steroid action and interaction in uterine metabolism. Recent Prog. Horm. Res. 8, 419-469.

Tauber, P.F., Wettich, W., Nohlen, M. \& Zaneveld, L.J.D. (1985) Diffusible proteins of the mucosa of the human cervix, uterus and fallopian tubes: distribution and variations during the menstrual cycle. Am. J. Obstet. Gynecol. 151, 1115-1125.

Tchernitchen, X., Tchernitchen, A. \& Galand, P. (1976) Dynamics of eosinophils in the uterus after estrogen administration. Differentiation 5, 151-154.

Thatcher, W.W., Wolfenson, D., Curl, J.S., Rico, L.E., 
Knickerbocker, J.J., Bazer, F.W. \& Drost, M. (1984) Prostaglandin dynamics associated with development of the bovine conceptus. Anim. Reprod. Sci. 7, 149-176.

Thie, M., Bochskanl, R. \& Kirchner, C. (1984) Purification and immunohistology of a glycoprotein secreted from the rabbit uterus before implantation. Cell Tiss. Res. 237, 155-160.

Thie, M., Bochskanl, R. \& Kirchner, C. (1986) Further characterization of the $\beta$-glycoprotein of the rabbit uterus. Biol. Reprod. 35, 683-689.

Verheugen, C., Pardridge, W.M., Judd, H.L. \& Chaudhuri, G. (1984) Differential permeability of uterine and liver vascular beds to estrogens and estrogen conjugates. $J$. clin. Endocr. Metab. 59, 1128-1132.

Walters, M.R., Lawrence, A.L. \& Hazelwood, R.L. (1979) Amino acid transport from the lumen of the rat uterus. Biol. Reprod. 20, 985-990.

Walters, M.R., Lawrence, A.L. \& Hazelwood, R.L. (1981) Sugar and amino acid transport from the rat uterine lumen: effects of estrogen and progesterone. Endocrinology 108, 1915-1919.

Wilson, J.M. \& King, B.F. (1986) Sorting and transepi- thelial transport of absorbed protein tracers: effects of temperature. Anat. Rec. 216, 33-39.

Winterhager, E. \& Kuhnel, W. (1982) Alterations in intercellular junctions of the uterine epithelium during the preimplantation phase in the rabbit. Cell Tissue Res. 224, 517-526.

Wira, C.R. \& Stern, J.E. (1986) Estradiol regulation of the secretory immune system in the female reproductive tract: $\operatorname{IgA}$ in uterine and vaginal secretions of rats following portacaval anastomosis. J. Steroid Biochem. 24, 33-37.

Wira, C.R., Hyde, E., Sandoe, C.P., Sullivan, D. \& Spencer, S. (1980) Cellular aspects of rat uterine IgA response to oestradiol and progesterone. J. Steroid Biochem. 12, 451-459.

Wira, C.R., Stern, J.E. \& Colby, E. (1984) Estradiol regulation of secretory component in the uterus of the rat: evidence for involvement of RNA synthesis. J. Immunol. 133, 2624-2628.

Ying, Y-K., Randolph, J.F., Maier, D.B., Kuslis, S.T., Chapitis, J. \& Riddick, D.H. (1986) Uterine fluid and prolactin secretion in the ovulating cynomolgus monkey. Am. J. Obstet. Gynecol. 155, 677-680. 